\title{
KINERJA ORGANISASI DIDUKUNG OLEH EPEMIMPINAN SPIRITUAL (SPIRITUAL LEADERSHIP) MELALUI KETERIKATAN KARYAWAN (EMPLOYEE ENGAGEMENT) (STUDI KASUS PADA SATUAN BRIMOB POLDA JAMBI)
}

\author{
Pria Premos $^{1)}$, Zulfina Adriani ${ }^{2)}$ \\ ${ }^{1)}$ Anggota Polri Di Polda Jambi \\ ${ }^{2)}$ Program Studi Magister Manajemen FEB Universitas Jambi \\ priapremos@gmail.com
}

\begin{abstract}
Abstrak
Penelitian ini bertujuan untuk mengetahui pengaruh kepemimpinan spiritual (spiritual leadership) terhadap keterikatan personil (employee engaged) di Satuan Brimob Polda Jambi serta untuk mengetahui pengaruh keterikatan personil (employee engaged) terhadap kinerja Satuan Brimob Polda Jambi dan untuk mengetahui pengaruh kepemimpinan spiritual (spiritual leadership) terhadap kinerja Satuan Brimob Polda Jambi melalui keterikatan personil (employee engaged). Penelitian ini adalah penelitian dengan menggunakan metode survei, yaitu metode pengumpulan data primer berdasarkan komunikasi antara peneliti dan responden. Data dalam penelitian ini berupa data subjek yang menyatakan opini, sikap, pengalaman, atau karakteristik subjek secara individual atau kelompok. Peneliti melakukan penyebaran kuisioner untuk menjawab pernyataan yang telah disiapkan. Penelitian ini dilaksanakan di Satuan Brimob Polda Jambi pada bulan November hingga Januari 2021. Subjek dalam penelitian ini adalah personil Satuan Brimob Polda Jambi sebanyak 205 personil. Pengumpulan data dalam penelitian ini menggunakan teknik kuisioner dan wawancara. Hasil penelitian menunjukkan bahwa hasil pengujian secara parsial antara kepemimpinan spiritual terhadap keterikatan karyawan, hasil pengujian secara parsial antara keterikatan karyawan terhadap kinerja organisasi, hasil pengujian secara parsial antara kepemimpinan spiritual terhadap kinerja organisasi pada Satuan Brimob Polda Jambi menunjukan nilai path coefficient, dengan demikian Hipotesis dapat diterima.
\end{abstract}

Kata Kunci: Kinerja Organisasi, Kepemimpinan Spritual, Keterikatan Karyawan Abstract
This study aims to determine the effect of spiritual leadership on employee engagement at
the Jambi Police Mobile Brigade Unit and to determine the effect of employee engaged on
the performance of the Jambi Regional Police Mobile Brigade Unit and to determine the
effect of spiritual leadership. to the performance of the Jambi Police Mobile Brigade Unit
through employee engagement. This research is a research using a survey method, namely
the primary data collection method based on the communication between the researcher
and the respondent. The data in this study is in the form of subject data which states
opinions, attitudes, experiences, or characteristics of the subject individually or in groups.
Researchers distributed questionnaires to answer the statements that had been prepared.
This research was conducted at the Jambi Police Mobile Brigade Unit from November to
January 2021. The subjects in this study were 205 personnel of the Jambi Police Mobile
Brigade Unit. Collecting data in this study using questionnaires and interviews. The
results showed that the partial test results between spiritual leadership and employee
engagement, the partial test results between employee attachment to organizational
performance, partial test results between spiritual leadership and organizational 
performance at the Jambi Police Mobile Brigade Unit showed the path coefficient value, thus the hypothesis can be found. be accepted.

Keywords: Organizational Performance, Spiritual Leadership, Employee Engagement

\section{PENDAHULUAN}

Manajemen yang dilaksanaan dalam sebuah organisasi merupakan kinerja dari organisasi, dimana kinerja organisasi dihasilkan dari suatu proses kepemimpinan dalam mempengaruhi aktivitas kelompok dengan kemampuan memperoleh kesepakatan pada tujuan bersama. Kinerja yang dihasilkan sesuai dengan tuntutan saat ini yakni perubahan baik internal maupun eksternal. Perubahan internal dari kinerja yang dihasilkan harus memiliki elemen penting seperti pengaruh/dukungan, usaha sukarela, dan pencapaian tujuan (Newstrom dan Davis, 2002).

Hubungan yang dibangun dalam setiap situasi menjadi peran yang sangat penting dalam membuat karyawan terikat. Keterikatan karyawan selain dengan organisasi, pimpinan juga berperan untuk membuat karyawan merasa terikat dan membangun komitmen terhadap kewajibannya dalam organisasi. Komitmen yang diberikan oleh karyawan akan membuat pekerjaan menjadi sukses, dan berpengaruh pada kinerja organisasi ssecara keseluruhan. Keterikatan yang dibangun akan menghasilkan ikatan emosional yang tinggi dari seorang karyawan yang rasakan terhadap organisasinya sehingga mempengaruhi karyawan untuk mengerahkan usaha yang bebas dan lebih besar untuk pekerjaannya (Risher, 2010).

Satbrimob Polda Jambi memiliki tugas melakukan perubahan, meningkatkan kemampuan personil yang siaga dalam waktu 24 Jam dalam hal Kamtibmas, sesuai dengan misi dari Polda Jambi yang mencerminkan koridor tugas. Satbrimob Polda Jambi sebagai kesatuan ditubuh Polda memiliki permasalahan terkait kinerja, kinerja yang dihasilkan berasal dari persoalan-persoalan yang ada ditubuh Satbrimob Polda Jambi.

Dari data yang diperoleh menunjukan peningkatan jumlah pelanggaran dalam 4 (empat tahun terakhir, peningkatan pelanggaran yang terjadi sebesar 57 persen pada tahun 2017, penurunan persentase peningkatan ditahun 2018 menjadi $22 \%$, meningkat lagi pada tahun 2019 menjadi 30 persen. Meskipun berfluktuatif namun dalam 4 tahun terakhir terjadi pelanggaran disiplin yang menunjukan bahwa terdapat fenomena emosional personil polisi secara internal.

Selain pelanggaran disiplin yang terjadi terdapat juga permohonan pindah dari satuan brimob ke kesatuan lainnya di Provinsi Jambi. Jumlah permohonan pindah yang ada di Brimob dalam 3 tahun terakhir menunjukan persentase yang meningkat. Pengajuan pindah personil Brimob, menunjukan persentasi yang meningkat, meski berfluktuasi. Namun persentasenya cukup besar, mengingat Brimob merupakan kesatuan yang memiliki tugas dan peran yang sangat berat, dengan tantangan yang sangat berat maka upaya untuk membuat personil merasa terlibat dan tetap bertahan, dalam melaksanakan tuntutan tugas maka diperlukan upaya untuk membuat personil Brimob melekat dalam tugas dan menghasilkan kinerja yang sesuai dengan yang diharapkan. Pimpinan harus melihat fenomena ini sebagai penentuan corak gaya kepemimpinan yang tepat agar persoalan ini dapat diminimalisir.

Berdasarkan uraian diatas maka penulis tertarik untuk melakukan penelitian mengenai "Pengaruh Kepemimpinan Spiritual (Spiritual Leadership) terhadap Kinerja Korps Brigadir Mobil (Brimob) melalui Keterikatan personil (employee engaged)" 


\section{TINJAUAN PUSTAKA}

\section{Kinerja Organisasi}

Kinerja organisasi secara konsep mengalami perkembangan (Barney, 2015), perkembangan terkait konsep kinerja ini dalam hal efektifitas, efisiensi, ekonomi, kualitas, konsistensi perilaku dan tindakan normative (Wade, David and Ronald Ricardo. 2001).

Kinerja (performance) menurut Daft (2010) adalah kemampuan untuk pencapaian tugas organisasi dengan menggunakan sumber daya secara efektif dan efisien. Sumber daya yang dimaksudkan meliputi sumber daya manusia, seluruh kekayaan, kapabilitas, proses organisasi, atribut perusahaan, informasi serta pengetahuan yang dikendalikan perusahaan.

Pengukuran kinerja organisasi maka penulis dalam penelitian ini membuat pengukuran/dimensi untuk kinerja organisasi adalah : 1). Konsistensi perilaku dan Tindakan normative; 2) Kapabilitas karyawan; 3) informasi dan pengetahuan karyawan; 4) Pelaksanaan kegiatan. (Wade, David and Ronald Ricardo. 2001, Dessler, 2007).

\section{Kepemimpinan Spiritual (Spiritual Leadership)}

Kepemimpinan spiritual hadir setelah penelitian-penelitian dilakukan terkait konsep kepemimpinan karismatik dan transformasional, dimana ditemukan kelemahankelemahan yang cukup serius dan koreksi yang dilakukan agar teori kepemimpinan menjadi lebih bermanfaat (Yukl, G. (2006)), kedua teori ini tidak menggambarkan pengaruh yang mendasar dalam penyelesaian masalah, dan secara spesifik bagaimana perilaku dari 2 gaya pemimpin ini terkait dalam proses penyelesaiannya.

Percy, (2003) dalam bukunya Going Deep. Exploring Spirituality in life and leadership, kepemimpinan spiritual yaitu kepemimpinan yang dapat dijalankan dengan formula 30/30/20/20, maksudnya yaitu seorang Spiritual Leadership menghabiskan 30\% waktunya untuk berfikir, dia mempercayai dan mengembangkan kemampuan otaknya, bisa dikatakan dia seorang yang berpikir realistis. $30 \%$ berikutnya adalah digunakan untuk komunikasi. baik komunikasi yang dilakukan didalam maupun luar organisasi, berusaha agar komunikasi berjalan efektif. $20 \%$ adalah untuk melakukan pengawasan dan pembinaan. Dan yang terakhir 20\% digunakan untuk operasional, dapat dikatakan dia menguasai tugas secara teknis. Atau sangat menguasai kondisi organisasi.

Kepemimpinan spiritual bertujuan untuk menciptakan visi dan nilai yang sesuai dengan keseluruhan strategi, pemberdayaan tim dan tingkat individu dan pada akhirnya akan mendorong peningkatan komitmen dan produktivitas organisasi yang tinggi (Louis Fry and Eleftheria Ege. 2017). Pertama, kepemimpinan diuji sebagai sebuah motivasi untuk mengubah teori kepemimpinan berbasis motivasi, kedua, mempercepat sebutan untuk spiritualitas ditempat kerja yang menggambarkan kebutuhan manusia secara universal, untuk kelangsungan hidup secara spiritual dan anggotanya, dan membedakan antara agama dan spiritualitas.

Dalam penelitian ini membuat pengukuran untuk spiritual adalah : 1). Visi ; 2) Harapan/keyakinan; 3) Tekat dan keyakinan; 4) Mebangun karakater; 5) Sebagai penjernih dan pengilham (Yukl, G., 2006; Percy, 2003; Louis Fry and Eleftheria Ege. 2017; Alannah Eileen Rafferty. 2004)

\section{Keterikatan Karyawan (Employee Engagement)}

Employee engagement merupakan pendekatan yang digunakan di tempat kerja yang bisa menghasilkan kondisi yang tepat bagi seluruh pegawai supaya bisa memberikan kinerja terbaik setiap harinya, karena kinerja merupakan hasil dari upaya yang 
dikeluarkan individu pada pekerjaannya untuk organisasi. Penelitian Kahn (2016) mendukung engagement sebagai konstruk yang melihat perbedaan diantara karyawan dan berapa banyak energy dan dedikasi diberikan di tempat kerja. Engagement memiliki konstruk yang multidimensional dimanaengagementbukan hanya ditataran emosional, tapi juga secara fisik dan kognitif (Vibrayani, 2012). Selanjutnya, May, D.R., Gilson, R.L., \& Harter , L.M., 2004) menyatakan bahwa karakteristik engagement memiliki 3 dimensi komponen yakni : komponen fisik berupa energi yang digunakan untuk melaksanakan pekerjaan, komponen emosi yaitu berupa dedikasi yang diberikan pada pekerjaan yang dilakukan oleh karyawan, serta komponen pikiran yaitu berupa keadaan dimana karyawan larut dalam pekerjaannya sehingga meluangkan hal-hal di sekelilingnya.

Berdasarkan uraian dan definisi sebelumnya maka penulis merangkum employe engagement merupakan keadaan dimana karyawan merasa positif dan puas terhadap pekerjaan yang menjadi tugasnya ditandai dengan semangat, dedikasi dan senang bagi karyawan, dalam bentuk kesadaran tanpa dipengaruhi oleh kejadian, objek dan perilaku tertentu (Schaufeli, W., \& Bakker, A. (2004); Martha (2011); Ivan T. Robertson and Cary Cooper. (2010)

Pengukuran keterikatan karyawan (employee engagement) merupakan dimensi yang akan digunakan dalam variable keterikatan karyawan (employee engagement). (Wiley \& Blackwell. 2009) :

Prinsip-Prinsip Dasar Employee Engagement

a. The Capacity to Engagement

b. The Motivation to Engagement

c. The Freedom to Engagement

d. The Focus of Strategic Engagement

Thomas, C. H. (2007) menyatakan dimensi employee engagement antara lain :

a. Kesiapan

1) Siap mendedikasikan diri pada pekerjaan

2) Memikirkan cara baru untuk bekerja lebih efektif

3) Semangat dalam melaksanakan pekerjaan

b. Kerelaan

1) Kesediaan memotivasi diri untuk mencapai keberhasilan

2) Kesediaan untuk bekerja keras atau bekerja ekstrakeras

c. Kebanggaan

1) Pekerjaan sebagai sumber kebanggan diri

2) Pekerjaan dikerjakan secara lengkap dan menyeluruh

3) Kesiapan mencurahkan jiwa bagi pekerjaan

\section{METODOLOGI PENELITIAN}

\section{Desain Penelitian}

Jenis penelitian ini menggunakan metode survei (Indriantoro, Nur and Bambang Supomo. 2014), yakni metode pengumpulan data primer berdasarkan komunikasi antara peneliti dan responden. Data dalam penelitian ini berupa data subjek yang menyatakan opini, sikap, pengalaman, atau karakteristik subjek secara individual atau kelompok. Peneliti akan melakukan penyebaran kuisioner untuk menjawab pernyataan yang telah disiapkan.

\section{Populasi dan Sampel}

Menurut Suyiono (2017) populasi merupakan wilayah generalisasi yang terdiri atas objek atau subjek di dalamnya mempunyai karakteristik dan kualitas tertentu yang 
ditetapkan oleh peneliti untuk dipelajari dan kemudiann ditarik kesimpulan. Populasi dalam penelitian ini adalah seluruh anggota Brimob di Polda Jambi yang berjumlah 717 personil.

Sampel adalah bagian dari jumlah dan karakteristik yang dimiliki populasi besar (Sugiyono, 2017). Sampel dalam penelitian ini adalah 205. Teknik sampling yang digunakan dalam penelitian ini adalah simple random samping yaitu dikatakan sederhana karena pengambilan anggota sampel dari populasi dilakukan secara acak tanpa memperhatikan strata yang ada. Teknik pengambilan sampel menggunakan rumus Slovin sehingga diperoleh jumlah sampel sebanyak 272 responden.

\section{Jenis dan Sumber Data}

Data primer dalam penelitian ini adalah jawaban atas kuisioner yang disebarkan kepada responden yang merupakan anggota Brimob Polda Jambi. Teknik pengumpulan data primer berupa kuisioner dengan jenis kuisioner tertutup. Jawaban setiap item instrumen yang menggunakan skala likert rentang 1-5 yang mempunyai gradasi dari sangat positif sampai sangat negatif, yang dapat berupa kata-kata (Sugiyono, 2017).

Menurut Sekaran \& Bougie (2013) data sekunder mengacu pada informasi yang dikumpulkan dari sumber data pendukung yang terkait dengan variable. Data sekunder dalam penelitian ini meliputi : profil, sejarah, visi dan misi, tujuan, struktur organisasi, serta dokumen lainnya yang relevan digunakan sebagai data pendukung penelitian, terkait dengan variabel yang akan diteliti.

\section{Teknik Analisis Data}

Analisis data yang digunakan dalam penelitian ini adalah analisis data kuantitatif, dengan penggunaan angka skala likert. Untuk mengukur secara kuantitatif pengaruh langsung variabel independent terhadap variabel denpenden melalui variabel mediasi digunakan alat analisis Structual Equation Model (SEM) Sofware yang digunakan dalam penelitian ini adalah Smart PLS 3.0. SEM berbasis co-variance, SEM-PLS dapat bekerja secara efisien dengan ukuran sampel yang kecil dan model yang kompleks. Selain itu PLS tidak membutuhkan banyak asumsi, data tidak terdistribusi normal. Menurut Ghozali (2015) menyebutkan model evaluasi PLS dilakukan dengan menilai outer model dan irner model.

\section{Uji Hipotesis}

Signifikasi dan analisis besarnya pengaruh variable independent secara parsial terhadap variable dependen maka model pengujian dalam penelitian dapat dilihat pada gambar dibawah ini.

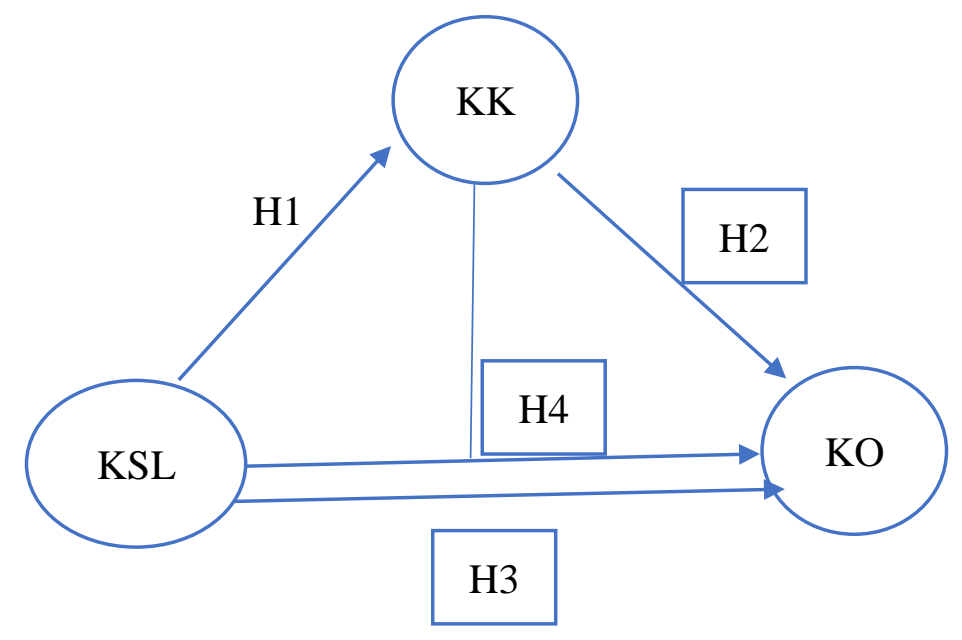


Keterangan :

KSL = Kepemimpinan Spiritual

$\mathrm{KO}=$ Kinerja Organisasi

$\mathrm{KK}=$ Employee Engagement (Keterikatan karyawan)

\section{Pengujian efek langsung (direct effect)}

Uji parsial digunakan untuk mengetahui apakah variabel-variabel independen secara parsial berpengaruh atau tidak terhadap variabel dependen. Caranya dengan melihat nilai koofisien parameter nilai. Signifikan t statistik pada Algorithma Bootstaping dengan memilih Report dan Pilih path Coeficient Ghozali dan laten (2015). Jika pada tingkat signifikatn $\mathrm{a}=5 \%(0,05)$, menghasikan koefisien paramater dan nilai statistik $\mathrm{t}>1,96$ dan signifikasi ( $\mathrm{p}$-value) $<0,05$ maka pengaruh variabel indenpenden terhadap variabel dependen dapat diterima dan jika koefisien paramater dan jka nilai statistik $t<1,96$ dan signifikasi ( $p$-value) $>0,05$ maka pengaruh variabel indenpenden terhadap variabel dependen ditolak.

\section{Pengujian efek tidak langsung (indirect effect)}

Pengujian efek tidak lansung dengan melibatkan variabel intervening dapat dilihat dari perbandingan pengaruh lansung dengan total effect (Ghozali 2015), apabila pengaruh lansung lebih kecil dari pada total effect maka terbukti bahwa variabel employee engagement sebagai variable intervening atau dapat juga melihat nilai probabilitas, dimana jika $\mathrm{P}$ values $<0,05$ maka variable Kepemimpinan Spiritual terhadap kinerja organisasi berpengaruh, begitu pula sebaliknya jika $\mathrm{P}$ Values $>0,05$ maka variable Kepemimpinan spiritual melalui employee engagement secara bersama-sama berpengaruh terhadap kinerja organisasi (Brimob).

\section{HASIL DAN PEMBAHASAN}

Karakteristik responden pada penelitian ini menggambarkan umur didominasi oleh personil berusia 36-45 tahun $(41,54 \%)$, dengan tingkat pendidikan terakhir Strata 1 (93,38\%), jabatan kesatuan BA YAN A POR dan lain-lain $(26,10 \%$ \& 28,68\%) serta tahun bergabung di kesatuan Brimob berkisat antara tahun 1996-2000.

Gambaran umum kepemimpinan spiritual pada Satbrimob Polda Jambi sangat baik, hal ini menggambarkan bahwa kepemimpinan spiritual mampu membawa personil menjadikan visi, harapan/iman, tekat keyakinan yang ditanamkan, serta mampu membangun karakter personil, serta berdiri menjadi penjernih dan pengilham. Artinya satbrimob sebagai kesatuan yang berdiri digarda depan dalam mempertahankan NKRI dan bela negara baik dalam maupun luar dari kesatuan tetap berprinsip darahku untuk bangsaku, sehingga tekat yang dibangun dengan penerapan gaya kepemimpinan spiritual akan terbentuk personil-personil handal.

Keterikatan karyawan, tergolong sangat baik terutama dimensi persepsi positif, konsistensi pimpinan dalam mentoring, namun terdapat indikator budaya organisasi personil merasa sudah mendapatkan keadilan dan kepercayaan cukup baik. Artinya keterikatan karyawan yang ada pada diri personil masih belum optimal pada dimensi budaya organisasi yang tercipta, masih ada personil yang belum mendapatkan rasa keadilan dan kepercayaan pada personil Satbrimob ini.

Kinerja Organisasi, kinerja satbrimob pada dimensi kapabilitas personil tergolong sangat baik, namun dimensi konsistensi perilaku dan Tindakan normative masih terdapat personil selalu menyelesaikan tugas dengan tepat waktu yang ditetapkan masih belum optimal, serta dimensi informasi dan pengetahuan personil masih terdapat personil yang 
memiliki tingkat pengetahuan terkait terorisme tergolong cukup baik. Artinya kinerja yang dihasilkan faktanya masih terdapat personil yang belum sesuai dengan tujuan dan target dari satbrimob dalam menyelesaikan tugas yang diberikan, hal ini sangat terkait dengan tingkat pengetahuan terkait terorisme masih belum optimal, padahal terorisme menjadi tanggung jawan satbrimob dalam mengatasi masalah ini.

\section{Hasil Analisis Model Pengukuran (Outer Model).}

Hasil konstruksi model dengan menggunakan program Partial least Square (PLS) dengan menginput masing-masing indikator pada penelitian ini. Pada penelitian ini semua variabel laten mempunyai indikator yang bersifat reflektif. Model pengukuran ini untuk menguji apakah model memiliki tingkat validitas dan reliabilitas yang disyaratkan, dengan menggunakan confirmatory factor analysis (CFA). Pengujian discriminant validity untuk membuktikan suatu indikator pada suatu konstruk mempunyai loading factor terbesar pada konstruk yang dibentuk. Hasil pengujian dapat dilihat pada gambar 1. berikut:

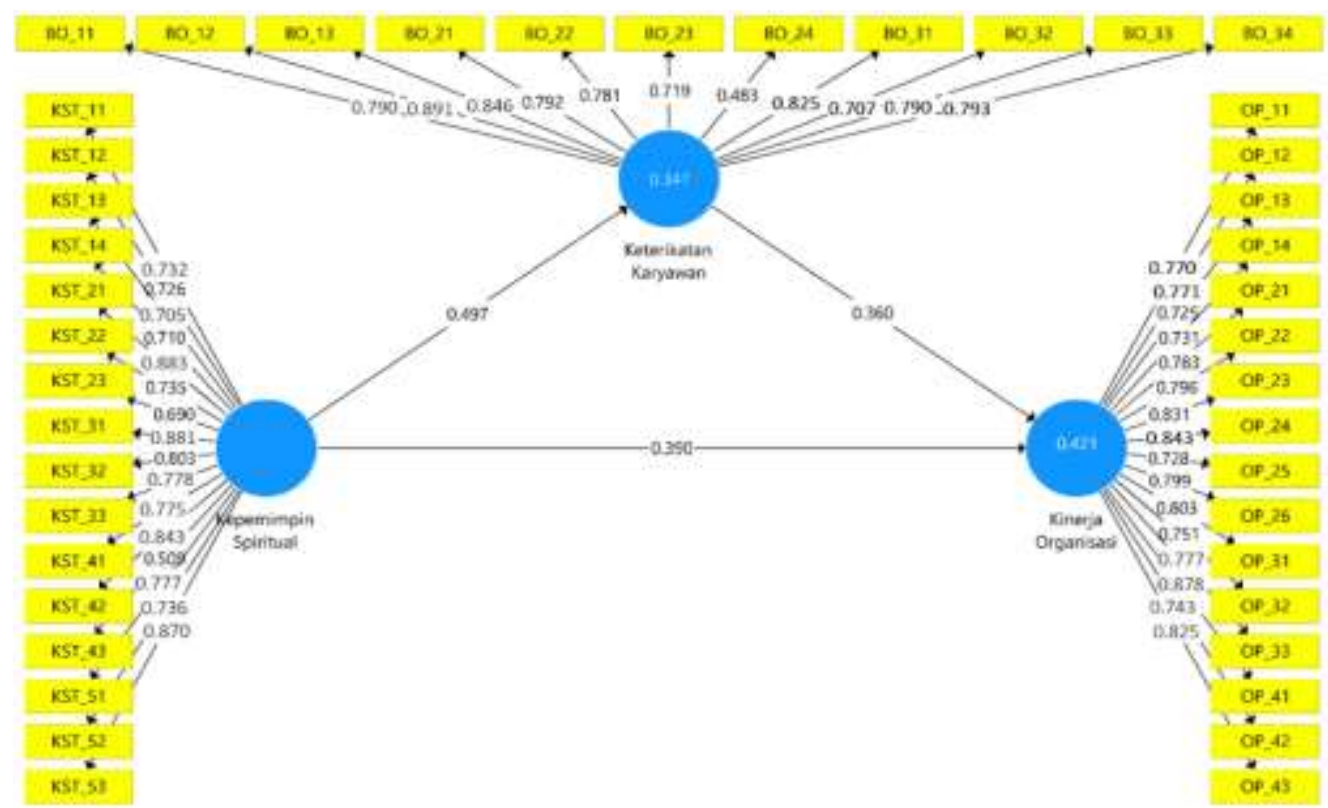

Gambar 1. Model Hasil Pengukuran

Nilai Path Coefficients dari variabel laten dapat dilihat pada tabel 2 berikut ini.

Tabel 2. Path Coefficients

\begin{tabular}{|l|c|c|r|r|r|l|}
\hline & $\begin{array}{c}\text { Original } \\
\text { Sample } \\
(\mathrm{O})\end{array}$ & $\begin{array}{c}\text { Sample } \\
\text { Mean } \\
(\mathrm{M})\end{array}$ & $\begin{array}{c}\text { Standard } \\
\text { Deviation } \\
(\text { STDEV })\end{array}$ & $\begin{array}{c}\text { T Statistics } \\
(\mid \mathrm{O} / \text { STDEV| })\end{array}$ & $\begin{array}{c}\text { P } \\
\text { Values }\end{array}$ & Hasil \\
\hline $\begin{array}{l}\text { Kepemimpinan Spiritual } \\
\text {-> Keterikatan Karyawan }\end{array}$ & 0,497 & 0,501 & 0,074 & 7,748 & 0,002 & Diterima \\
\hline $\begin{array}{l}\text { Kepemimpinan Spiritual } \\
\text { - Kinerja Organisasi }\end{array}$ & 0,390 & 0,393 & 0,193 & 1,991 & 0,047 & Diterima \\
\hline $\begin{array}{l}\text { Keterikatan Karyawan } \\
\text { > Kinerja Organisasi }\end{array}$ & 0,360 & 0,382 & 0,175 & 2,379 & 0,018 & Diterima \\
\hline $\begin{array}{l}\text { Karyawan -> Kinerja } \\
\text { Organisasi }\end{array}$ & & & & & & \\
\hline
\end{tabular}

Sumber : Data diolah,2021

Nilai $T$ statistic > 1,96 dan P Value dengan tingkat signifikan 0,05 
Berdasarkan gambar 1 tersebut dapat dilihat bahwa semua indikator dari ketiga variabel bervariasi dalam merefleksikan hubungan pada variable kinerja orgnisasi menggambarkan loading factor yang baik yaitu tercermin dari semua nilai loading factor yang lebih besar (>) 0,60. Namun variabel kepemimpinan spiritual terdapat nilai loading factor $(<)$ 0,60 pada KST_43 dengan nilai loading factor sebesar 0,509. Sedangkan pada variabel keterikatan karyawan juga terdapat nilai loading factor $(<)$ 0,60 pada BO_24 dengan nilai loading factor sebesar 0,483. Nilai loading faktor dapat dilihat pada tabel 5.13 berikut ini.

Uji convergent validity digunakan untuk menguji unidimensional dari masingmasing konstruk yang dilihat dari nilai indikator loading factor yang lebih besar dari 0,6 maka dianggap signifikan.

\section{Validitas dan Reliabilitas Model.}

Tingkat validitas sebuah model penelitian yang menggunakan partial least square(PLS), dimana validitas model dilihat dari nilai average variance extracted (AVE) sementara reliabilitas model dapat dilihat dari nilai Composite reliability dan Cronbach"s Alpha. Berikut hasil pengujian validitas kontruk dengan menggunak AVE :

Tabel 2. Construct Reliability and Validity

\begin{tabular}{|l|c|c|c|c|}
\hline & $\begin{array}{c}\text { Cronbach's } \\
\text { Alpha }\end{array}$ & rho_A & $\begin{array}{c}\text { Composite } \\
\text { Reliability }\end{array}$ & $\begin{array}{c}\text { Average Variance } \\
\text { Extracted (AVE) }\end{array}$ \\
\hline Kepemimpinan Spiritual & 0,915 & 0,915 & 0,921 & 0,628 \\
\hline Keterikatan Karyawan & 0,769 & 0,830 & 0,819 & 0,719 \\
\hline Kinerja Organisasi & 0,906 & 0,914 & 0,923 & 0,649 \\
\hline
\end{tabular}

Sumber : Data diolah , 2021

Hasi pengujian yang disajikan pada tabel 2 menunjukan bahwa nilai AVE variabel laten $>0.50$, denan demikian dapat dikatakan bahwa semua variabel laten yang diestimasi dinyatakan valid. Begitu juga dengan hasil pengujian reliabilitas konstruk menunjukan nilai composite reliability dan Cronbach's Alpha dari variabel laten $>0,70$, sehingga semua variabel laten dalam model yang diestimasi dinyatakan reliabel.

\section{Pengujiam Model Struktural (Structural Model)}

Pengujian model yang dilakukan untuk memperlihatkan keterkaitan antara variabel laten. Uji ini dilakukan untuk memastikan bahwa model yang digunakan akurat. Berikut hasil evaluasi untuk variabel kepemimpinan spiritual dan keterlibatan karyawan.

Tabel 3. Nilai R Square

\begin{tabular}{|l|r|r|}
\hline & R Square & R Square Adjusted \\
\hline Keterikatan Karyawan & 0.347 & 0.339 \\
\hline Kinerja Organisasi & 0,421 & 0,409 \\
\hline
\end{tabular}

Sumber : Data diolah, 2021

Hasil pengujian yang ditampilkan pada tabel 3 menunjukan nilai $\mathrm{R}^{2}$ dan $\mathrm{R}^{2}$ Adjusted keterikatan karyawan sebesar 0,35 dan 0,34>0,3 , dengan kriteria sebesar 0,3, artinya kepemimpinan spiritual mampu memberikan kontribusi atau pengaruh sebesar 0,35 terhadap keterlibatan karyawan. Begitu juga dengan kinerja organisasi diperoleh nilai sebesar 0,42 dan 0,41>0,3 , artinya kepemimpinan spiritual dan keterikatan karyawan mampu memberikan kontribusi atau pengaruh sebesar 0,42 terhadap kinerja organisasi. 
Sehingga dapat disimpulkan bahwa model penelitian dengan hasil yang didapat dan besar dari nilai kriteria termasuk moderat dan model penelitian didukung oleh kondisi empiris.

Model yang dibangun dalam penelitian ini adalah sebagai berikut :

Model $1: \mathrm{KK}=0,497 \mathrm{KST}+\zeta 1 \ldots \ldots$.

Hasil pengujian model 1 memperlihatkan bahwa kepemimpinan spiritual berpengaruh positif terhadap keterlibatan karyawan yang dibangun oleh Satbrimob Polda Jambi. Pengaruh positif ini dapat dilihat dari nilai koefisien jalur (tabel 5.13) variabel menunjukan nilai positif yaitu sebesar 0,497 untuk kepemimpinan spiritual. Hal ini menunjukan bahwa semakin baik kepemimpinan spiritual diterapkan maka semakin meningkat keterikatan personil sebesar $50 \%$ pada Satbrimob Polda Jambi. Lebih lanjut, dapat dilihat dari nilai koefisien jalur, bahwa kepemimpinan spiritual terhadap keterikatan karyawan dimana t-statistik $(7,748)>1,96$ artinya hipotesis diterima. Hasil ini memberikan gambar bahwa SatBimob akan meningkat kinerjanya jika didukung oleh pimpinan yang memiliki spiritual tinggi sehingga dapat membawa SatBrimob Polda Jambi menjadi lebih baik sebagai garda terdepan dalam mempertahankan ketahanan negara dan daerah.

Hasil pengujian parameter untuk model 2 dapat dilihat pada model berikut:

Model $2: \quad$ Model $2: \mathrm{KO}=0,390 \mathrm{KST}+0,360 \mathrm{KK}+\zeta 1 \ldots \ldots$.

Hasil model 2 memperlihatkan bahwa variabel kepemimpinan spiritual dan keterikatan karyawa berpengaruh positif dan signifikan terhadap kinerja organisasi SatBrimob Polda Jambi. Pengaruh positif ini dapat dilihat dari nilai koefisien jalur yang menunjukan nilai positif dengan R2 dari kedua variabel laten, dimana kinerja organisasi dibentuk oleh kepemimpinan spiritual sebesar 39\% dan keterikatan karyawan berkontribusi sebesar $36 \%$ terhadap kinerja organisasi. Hal ini menunjukan bahwa dengan nilai persentasi kedua variabel laten secara bersamaan makan peningkatan kinerja organisasi semakin baik dengan kontribusi kedua variabel sesuai model yang terbentuk di Satbrimob Polda Jambi.

Hasil pengujian secara parsial antara kepemimpinan spiritual terhadap keterikatan karyawan pada Satbrimob Polda Jambi menunjukan nilai path coefficient sebesar 0,497 tstatistic 7,748 > t-tabel 1,96 dan pada P-value 0,002 < tingkat signifikansi 0,05. Dengan demikian Hipotesis yang menyatakan bahwa Kepemimpinan spiritual berpengaruh positif terhadap keterikatan karyawan pada Satbrimob Polda Jambi dapat diterima. Hasil ini berarti bahwa semakin baik pelaksanaan kepemimpinan spiritual maka semakin baik keterikatan karyawan dilakukan oleh Satbrimob Polda Jambi. Hal ini sesuai dengan fakta bahwa keterikatan karyawan tidak bisa semata dengan atribut yang dibanggakan sebagai tantara bagi polisi dan nama besar gegana yang disandang, keterikatan karyawan dibangun berdasarkan pada tingkat spiritual seorang pimpinan, terutama dalam hal peningkatan iman, tekat dan keyakinan sehingga terbentuk karakter dengan spiritual yang baik, dan yang utama memposisikan diri sebagai penjernih dan pengilham bagi personil Satbrimob Polda Jambi.

Hasil pengujian secara parsial antara Keterikatan Karyawan terhadap Kinerja organisasi pada Satbrimob Polda Jambi menunjukan nilai path coefficient sebesar 0,360 t-statistic 2,379 > t-tabel 1,96 dan pada P-value 0,0018 < tingkat signifikansi 0,05. Dengan demikian Hipotesis yang menyatakan bahwa keterikatan karyawan berpengaruh 
positif terhadap Kinerja organisasi pada Satbrimob Polda Jambi dapat diterima. Hasil ini berarti bahwa semakin baik peningkatan keterikatan karyawan maka semakin baik kinerja organisasi yang dihasilkan oleh Satbrimob Polda Jambi. Hal ini mengindikasikan bahwa kenaikan jumlah keterikatan karyawan maka semakin baik kinerja organisasi, dimana budaya organisasi yang terbentuk, meningkatnya persepsi yang positif, serta konsisten pimpinan dalam mementor anggota akan berdampak pada peningkatan kinerja organisasi.

Hasil pengujian secara parsial antara kepemimpinan spiritual terhadap Kinerja organisasi pada Satbrimob Polda Jambi menunjukan nilai path coefficient sebesar 0,390 t-statistic 1,199 > t-tabel 1,96 dan pada P-value 0,0047 < tingkat signifikansi 0,05. Dengan demikian Hipotesis yang menyatakan bahwa kepemimpinan spritual berpengaruh positif terhadap Kinerja organisasi pada Satbrimob Polda Jambi dapat diterima. Artinya semakin baik penerapan gaya kepemimpinan spiritual maka semakin baik kinerja organisasi pada Satbrimob Polda Jambi. Hal ini mengindikasikan bahwa penerapan visi sebagai induk kinerja, peningkatan iman personil, memotivasi tekat dan keyakinan anggota serta membangun karakter personil dan menjernihkan suasana dengan berfungsi sebagai pengilham akan membuat personil Satbrimob meningkat kinerjanya yang berdampak pada peningkatan kinerja Satbrimob.

Hasil pengujian secara simultan antara kepemimpinan spiritual dan keterikatan karyawan terhadap Kinerja organisasi pada Satbrimob Polda Jambi menunjukan nilai path coefficient sebesar 0, 437, t-statistic 2,983 > t-tabel 1,96 dan pada P-value 0,0000 < tingkat signifikansi 0,05. Dengan demikian Hipotesis yang menyatakan bahwa kepemimpinan spritual dan keterikatan karyawan berpengaruh positif terhadap Kinerja organisasi pada Satbrimob Polda Jambi dapat diterima. Artinya semakin baik penerapan gaya kepemimpinan spiritual dan peningkatan keterikatan karyawan maka semakin baik kinerja organisasi pada Satbrimob Polda Jambi. Hal ini mengindikasikan bahwa penerapan gaya kepemimpinan spiritual bersama-sama dengan keterikatan karyawan akan dapat meningkatkan kinerja Satbrimob, karena dimensi dari kepemimpinan spiritual telah diterapkan bersama-sama dengan dimensi keterikatan karyawan sehingga secara otomatis kinerja Satbrimob juga meningkat.

\section{Pembahasan}

Secara keseluruhan hasil penelitian ini mengungkapkan bahwa kepemimpinan spiritual sebagai gaya kepemimpinan yang diterapkan pada SatBrimob Polda Jambi sudah terimplementasi dengan baik melalui program keterikatan karyawan dalam mendukung meningkatnya kinerja SatBrimob Polda Jambi. Kinerja SatBrimob dari aspek spiritual membutuhkan dukungan program spiritual dan dukungan peningkatan keimanan untuk mendukung kinerja individu yang membutuhkan keseimbangan antara spiritual dan kestabilan emosi. Melalui keterikatan karyawan dalam bentuk indikator yang diteliti maka akan memudahkan pimpinan dalam membangun karakter dan menghasilkan peningkatan kreatifitas dan kemampuan sehingga kinerja organisasi akan tercapai secara optimal. Hasil pengujian hipotesis semua mendukung hipotesis alternatif yang diajukan, kecuali pengaruh langsung, namun pengaruh tidak langsung antara kepemimpinan spiritual terhadap kinerja organisasi berpenaruh positif dan signifikan Ketika keterlibatan karyawan menjadi variabel intervening sehingga kinerja SatBrimob dapat meningkat.

Penelitian ini menghasilkan model kinerja SatBrimob yang didukung oleh kepemimpinan spiritual melalui keterikatan karyawan, dan merupakan penelitian pertama yang menggunakan konstruk kepemimpinan spiritual dan keterikatan karyawan serta 
pengaruhnya kepada kinerja SatBrimob Polda Jambi. Penelitian sebelumnya kepemimpinan spiritual berpengaruh langsung pada kinerja SatBrimob dan mengabaikan keterikatan karyawan (Louis Fry and Eleftheria Ege. 2017; Garg Naval (2017)).

Keterlibatan karyawan menjembatani kepemimpinan spiritual dalam meningkatkan kinerja SatBrimob Polda Jambi menggunakan pendekatan intermediasi dalam bentuk keterlibatan karyawan dapat meningkatkan kinerja SatBrimob yang belum pernah diteliti pada objek yang sama dimana penelitian sebelumnya menggunakan dimensi yang berbeda dengan dimensi yang digunakan pada penelitian ini.

\section{SIMPULAN DAN SARAN}

\section{Simpulan}

1. Hasil pengujian secara parsial antara kepemimpinan spiritual terhadap keterikatan karyawan pada Satbrimob Polda Jambi menunjukan bahwa Kepemimpinan spiritual berpengaruh positif terhadap keterikatan karyawan pada Satbrimob Polda Jambi. Hasil ini berarti bahwa semakin baik pelaksanaan kepemimpinan spiritual maka semakin baik keterikatan karyawan dilakukan oleh Satbrimob Polda Jambi.

2. Hipotesis yang menyatakan bahwa keterikatan karyawan berpengaruh positif terhadap Kinerja organisasi pada Satbrimob Polda Jambi dapat diterima. Hasil ini berarti bahwa semakin baik peningkatan keterikatan karyawan maka semakin baik kinerja organisasi yang dihasilkan oleh Satbrimob Polda Jambi. Hal ini mengindikasikan bahwa kenaikan jumlah keterikatan karyawan maka semakin baik kinerja organisasi, dimana budaya organisasi yang terbentuk, meningkatnya persepsi yang positif, serta konsisten pimpinan dalam mementor anggota akan berdampak pada peningkatan kinerja organisasi.

3. Hipotesis yang menyatakan bahwa kepemimpinan spritual berpengaruh positif terhadap Kinerja organisasi pada Satbrimob Polda Jambi dapat diterima. Artinya semakin baik penerapan gaya kepemimpinan spiritual maka semakin baik kinerja organisasi pada Satbrimob Polda Jambi. Hal ini mengindikasikan bahwa penerapan visi sebagai induk kinerja, peningkatan iman personil, memotivasi tekat dan keyakinan anggota serta membangun karakter personil dan menjernihkan suasana dengan berfungsi sebagai pengilham akan membuat personil Satbrimob meningkat kinerjanya yang berdampak pada peningkatan kinerja Satbrimob.

4. Hipotesis yang menyatakan bahwa kepemimpinan spritual dan keterikatan karyawan berpengaruh positif terhadap Kinerja organisasi pada Satbrimob Polda Jambi dapat diterima. Artinya semakin baik penerapan gaya kepemimpinan spiritual dan peningkatan keterikatan karyawan maka semakin baik kinerja organisasi pada Satbrimob Polda Jambi. Hal ini mengindikasikan bahwa penerapan gaya kepemimpinan spiritual bersama-sama dengan keterikatan karyawan akan dapat meningkatkan kinerja Satbrimob, karena dimensi dari kepemimpinan spiritual telah diterapkan bersama-sama dengan dimensi keterikatan karyawan sehingga secara otomatis kinerja Satbrimob juga meningkat.

\section{Saran}

Penelitian ini menguji variabel gaya kepemimpinan spiritual terhadap kinerja Satbrimob Polda Jambi melalui variabel keterikatan karyawan. Saran untuk peneliti lain agar menggunakan variabel selain dari variabel penelitian ini. 
Objek penelitian pada SatBrimob Polda Jambi, saran untuk peneliti lain agar meneliti Satbrimob lain diluar daerah di seluruh Indonesia untuk perbandingan dari penelitian tersebut.

Saran praktis bagi SatBrimob Polda Jambi : 1. Pentingnya penerapan gaya kepemimpinan spiritual karena tugas dan tanggung jawab personil Satbrimob sangat dekat dengan bahaya serta mengorbankan nyawa sebagai pasukan terdepan di tubuh Polri. 2. Keterikatan karyawan sangat penting dilakukan agar personil tetap teguh dengan tekat dan keyakinan dalam budaya yang dibentuk namun pimpinan harus memberikan keadilan dan kepercayaan terhadap masing-masing personil. 3. Kinerja organisasi Satbrimob harus optimal sehingga penyelesaian tugas sesuai waktu yang ditargetkan tercapai dan meningkatkan pengetahuan terkait terorisme secara kontiniu karena teroris memiliki strategi yang selalu berubah - ubah dalam melancarkan aksinya.

\section{DAFTAR PUSTAKA}

Alannah Eileen Rafferty. 2004. Dimensions of Transformational Leadership: Conceptual and Empirical Extensions. The Leadership Quarterly 15(3):329-354. DOI: 10.1016/j.leaqua.2004.02.009 Tobroni. (2005). The spiritual leadership. Malang: UMM Press.

Bougie, \& Sekaran. (2013). Edisi 5, Research Methods for Business: A skill Building Approach. New York: John wiley@Sons.

Dessler, Gary. 2007. Manajemen Sumber Daya Manusia. Jakarta : PT. Indeks.Erman Anom, 2008. Lex Jurnalica Vol.5 No. 3,

Garg Naval (2017), Workplace Spirituality and Organizational Performance in Indian Context: Mediating Effect of Organizational Commitment, Work Motivation and Employee Engagement, South Asian Journal of Human Resources Management 4(2) 191-211 2017 SAGE Publications India Private Limited SAGE Publications sagepub.in/home.nav

Ghozali, Imam (2015). Aplikasi Analisis Multivariate Dengan Program SPSS. Cetakan Keempat. Semarang: Badan Penerbit Universitas Diponegoro.

Indriantoro, Nur and Bambang Supomo. 2014. Metodologi Penelitian Bisnis Untuk Akuntansi \& Manajemen. Edisi 1. Cetakan ke-12. Yogyakarta: BPFE.

Ivan T. Robertson and Cary Cooper. 2010. Full Engagement: the Integration of Employee Engagement and Psychological Well-Being. Leadership \& Organization Development Journal 31(4): 324-336. DOI: 10.1108/01437731011043348

Louis Fry and Eleftheria Ege. 2017. Spiritual Leadership: Embedding sustainability in the triple bottom line. Graziadio Business Report 20 (3)

May, D.R., Gilson, R.L., \& Harter , L.M., 2004. The psychological conditions of meaningfulness, safet and availability and tehe engagement of the human spirit at work. Journal of Occupational Psychology, 77, 11-37

Newstrom, John W. and Keith Davis, Organizational Behavior, Human Behavior at work. New Delhi: Tata Mc GrawHill Publishing Company Limited 2002.

Percy, Ian. (2003). Going deep: Exploring Spirituality in Life and Leadership. Arizona: Inspired Production Press

Risher (2010). Don't Overlook Frontline Supervisors. Public Manager, 39 (3): 74-76.

Schaufeli, W., \& Bakker, A. (2004) UWES Utrecht Work Engagement Scale Preliminary Manual. Occupational Health Psychology Unit Utrecht University, Utrecht 
Sugiyono. 2017. Metode Penelitian: Kuantitatif, Kualitatif, Dan R\&D. Cetakan ke27. Bandung: Alfabeta.

Thomas, C. H. (2007), “A New Measurement Scale for Employee Engagement: Scale Development, Pilot Test and Replication" dalam Academy of Management Proceedings, pp. 1-6.

Vibrayani. 2012. Peran Transformasional Leadership terhadap Employee Engagement. UGM: Tesis Fakultas Ekonomika dan Bisnis

Yukl, G. (2006). Kepemimpinan Dalam Organisasi. Edisi Bahasa Indonesia. Jakarta: PT. Indeks

Wade, David and Ronald Ricardo. 2001. Corporate Performance Management. How to Build a better Organization Trough Management-Driven Strategic Alligment. Butterworth Heinemann USA or http://www.bh.com.

Wiley \& Blackwell. 2009. Employee Engagement : Tools for Analysis, Practice, and Competitive Advantage. 